\title{
Nonuniform Carrier Trapping among Quantum Dots
}

\author{
Yi-Shin Su, Wei-Che Chang and Ching-Fuh Lin ${ }^{1}$ \\ Graduate Institute of Electro-Optical Engineering \\ also with Department of Electrical Engineering and Graduate Institute of Electronics Engineering \\ National Taiwan University Taipei 106, Taiwan ROC
}

\begin{abstract}
In quantum-dot (QD) structures, carriers do not distribute uniformly among QDs. Carriers tend to distribute at larger QDs. Combined with state filling effect, carrier will populate larger QDs first. Then, carrier will populate smaller QDs at higher injection density. The nonuniform carrier distribution also leads to the separation of two emission peaks with increasing current. On the fabricated devices, the photon energy difference between the two peaks increased from $70.8 \mathrm{meV}$ at $60 \mathrm{~mA}$ to $78 \mathrm{meV}$ at $160 \mathrm{~mA}$. By observing the peak separation, the tendency of carrier distribution can be identified.
\end{abstract}

Index Terms - InAs quantum dot, broadband semiconductor amplifier, semiconductor devices, nonuniform carrier distribution, quantum dot.

\section{INTRODUCTION}

Quantum dot (QD) devices have the advantage of high differential gain, low threshold current and improved efficiency [1] because they are supposed to have the unique delta function like density of states. However, growing single-size QDs is difficult. On the other hand, some researchers take advantage of the size fluctuation of QDs and demonstrate tunable lasers with more than $200 \mathrm{~nm}$ tuning range [2]. In this case, the distribution of carriers among QDs becomes important. Nonuniform carrier distribution encountered nonidentical MQWs usually occur, so broadband devices using nonidentical MQWs cannot be easily achieved[3]. In comparison, Because QDs are distributed in the 2-D epi-growth plane, it is easier to obtain better uniformity of carrier distribution among QDs for broadband applications. However, the carrier distribution among QDs is still not really uniform. When the QDs do not have a single size, their corresponding quantized energy levels have different positions. Thus, the QDs should have different carrier capture ability and different population probabilities. Here we discover that the injected carriers are not trapped among those QDs uniformly. At the low current level, the carriers tend to be trapped in large QDs. When the current level is increased, small QDs gradually trap carriers with increasing number.

\section{ACTIVE LAYER DESIGN}

The studied QD structure is grown on a GaAs substrate. The InAs QDs are grown within GaAs/ $\mathrm{In}_{0.15} \mathrm{Ga}_{0.85}$ As QWs to enhance carrier capture. The $\mathrm{p}$ and $\mathrm{n}$ type cladding layers are $\mathrm{Al}_{0.35} \mathrm{Ga}_{0.65} \mathrm{As}$ doped with $\mathrm{C}$ and $\mathrm{Si}$, respectively. The contact layer is GaAs with $5 \times 10^{19} \mathrm{~cm}^{-3}$ doping level. Two types of QD layers for $1.24 \mu \mathrm{m}$ emission and $1.28 \mu \mathrm{m}$ emission are grown alternatively in the active layer as shown in table I. Devices are fabricated on a wafer with the active region containing several layers of QDs. The QDs are intentionally grown to have a large size fluctuation. Whether the carriers are trapped in QDs uniformly or nonuniformly can be clarified from the spectrum measurement of the devices.

TABLE I

SUMMARY OF ACTIVE LAYER STRUCTURE

\begin{tabular}{|l|l|l|l|l|l|}
\hline Material & Group & Repeat & $\begin{array}{l}\text { Thick } \\
(\mathrm{nm})\end{array}$ & Doping & Type \\
\hline $\mathrm{GaAs}$ & & & 100 & $5 \mathrm{e} 19$ & $\mathrm{P}$ \\
\hline $\mathrm{Al}(\mathrm{x}) \mathrm{Ga}(1-\mathrm{x}) \mathrm{As}$ & & & 20 & $3 \mathrm{e} 18$ & $\mathrm{P}$ \\
\hline $\mathrm{Al}(\mathrm{x}) \mathrm{Ga}(1-\mathrm{x}) \mathrm{As}$ & & & 700 & $1 \mathrm{e} 18$ & $\mathrm{P}$ \\
\hline $\mathrm{Al}(\mathrm{x}) \mathrm{Ga}(1-\mathrm{x}) \mathrm{As}$ & & & 500 & $5 \mathrm{e} 17$ & $\mathrm{P}$ \\
\hline $\mathrm{GaAs}$ & 2 & 5 & 35 & & $\mathrm{U} / \mathrm{D}$ \\
\hline $\mathrm{In}(\mathrm{x}) \mathrm{Ga}(1-\mathrm{x}) \mathrm{As}$ & 2 & 5 & 5 & & $\mathrm{U} / \mathrm{D}$ \\
\hline $\mathrm{InAs}(\mathrm{for} 1.24 \mathrm{um})$ & 2 & 5 & 0.7 & & $\mathrm{U} / \mathrm{D}$ \\
\hline $\mathrm{GaAs}$ & 2 & 5 & 35 & & $\mathrm{U} / \mathrm{D}$ \\
\hline $\mathrm{In}(\mathrm{x}) \mathrm{Ga}(1-\mathrm{x}) \mathrm{As}$ & 2 & 5 & 5 & & $\mathrm{U} / \mathrm{D}$ \\
\hline $\mathrm{InAs}(\mathrm{for} 1.28 \mathrm{um})$ & 2 & 5 & 0.8 & & $\mathrm{U} / \mathrm{D}$ \\
\hline $\mathrm{GaAs}$ & & & 35 & & $\mathrm{U} / \mathrm{D}$ \\
\hline $\mathrm{Al}(\mathrm{x}) \mathrm{Ga}(1-\mathrm{x}) \mathrm{As}$ & & & 500 & $5 \mathrm{e} 17$ & $\mathrm{~N}$ \\
\hline $\mathrm{Al}(\mathrm{x}) \mathrm{Ga}(1-\mathrm{x}) \mathrm{As}$ & & & 1000 & $1 \mathrm{e} 18$ & $\mathrm{~N}$ \\
\hline $\mathrm{Al}(\mathrm{x}) \mathrm{Ga}(1-\mathrm{x}) \mathrm{As}$ & & & 20 & $3 \mathrm{e} 18$ & $\mathrm{~N}$ \\
\hline
\end{tabular}




\section{DEVICE FABRICATION}

Devices with an optical-amplifier structure are fabricated on this wafer. The devices use double channel ridge waveguides. The channels are etched by $\mathrm{HBr}: \mathrm{HCl}: \mathrm{H}_{2} \mathrm{O}_{2}: \mathrm{H}_{2} \mathrm{O}$ and the waveguide direction is tilted by 7 degrees. In this way, the effective reflection of cleaved facet is reduced to prevent Fabry-Perot oscillation, so spectrum measurement directly reflects the quantized states. After waveguide etch, silicon oxide deposited by plasma enhanced chemical vapor deposition under $300^{\circ} \mathrm{C}$ is applied as an insulation layer. The dielectric layer on top of the waveguide is removed by reactive ion etch to allow current injection. The electrical contact on top of the waveguide is e-beam deposited $\mathrm{Ti} / \mathrm{Pt} / \mathrm{Au}$ layers followed by $450^{\prime} \mathrm{C}$ rapid thermal annealing. The wafer is lapped down to $120 \mu \mathrm{m}$ thickness. The backside is polished and e-beam deposited $\mathrm{AuGa} / \mathrm{Ni} / \mathrm{Au}$ is applied for ohmic contact at the n-side. Finally, the wafer is cleaved to devices with $800 \mu \mathrm{m}, 500 \mu \mathrm{m}$, and $350 \mu \mathrm{m}$ chip length.

\section{Device Performance}

The EL spectrums of the devices are measured without bonding. During EL spectrum measurement, the environment temperature is controlled at $22{ }^{\circ} \mathrm{C}(295 \mathrm{~K})$. The current source used is a HP8114A pulse source. Pulse repetition rate is $1 \mathrm{kHz}$, and pulse width $1 \mu \mathrm{s}(0.1 \%$ duty cycle). The emitted light is coupled to a multimode fiber and feed into a CM110 monochrometer. The setup is shown in figure 1.

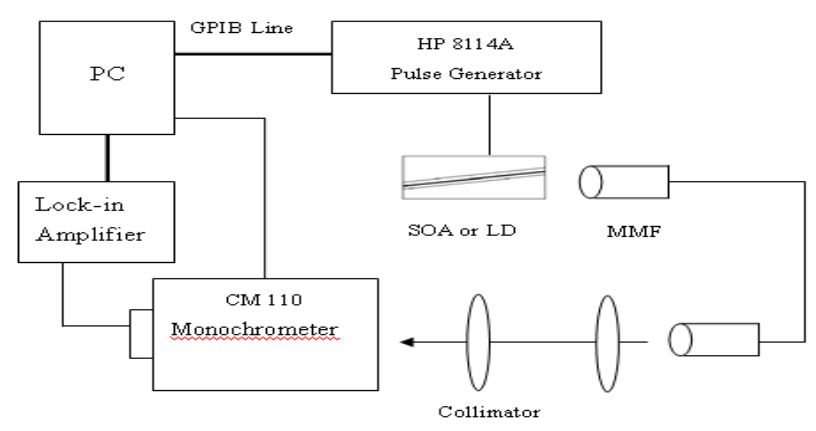

Fig. 1. The setup of spectrum measurement.

Figure 2 is the measured EL spectrum of the $800 \mu \mathrm{m}$ device. The spectrum has two peaks at $1.25 \mu \mathrm{m}$ and $1.17 \mu \mathrm{m}$. They correspond to the first quantized state and second quantized state of the QDs. In addition, extra signals can be observed between $1100 \mathrm{~nm}$ and $1000 \mathrm{~nm}$ with $240 \mathrm{~mA}$ and $320 \mathrm{~mA}$ injection current. This is considered to be the contribution of energy states in GaAs/InGaAs QWs.

The peak emission power of the $1.25 \mu \mathrm{m}$ peak saturates at $200 \mathrm{~mA}$. Its peak position red shifts with increased current. This peak is at $1250 \mathrm{~nm}$ with $20 \mathrm{~mA}$ injection. It moves to $1266 \mathrm{~nm}$ when the injection current is increased to $400 \mathrm{~mA}$. The peak emission power of the $1.17 \mu \mathrm{m}$ peak saturates at $320 \mathrm{~mA}$. The peak position blue shifts when the current is increased from $60 \mathrm{~mA}$ to $160 \mathrm{~mA}$. It shifts back to $1164 \mathrm{~nm}$ when the current is increased to $400 \mathrm{~mA}$. The emission of $\mathrm{GaAs} / \mathrm{InGaAs}$ QWs can only be observed with more than $240 \mathrm{~mA}$ injection.

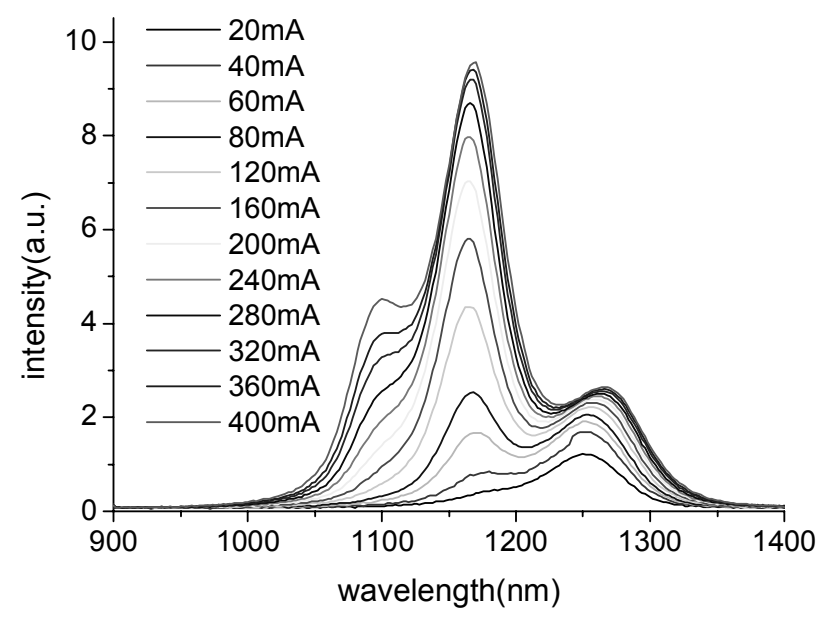

Fig. 2. The EL spectrum of $800 \mu \mathrm{m}$ device .

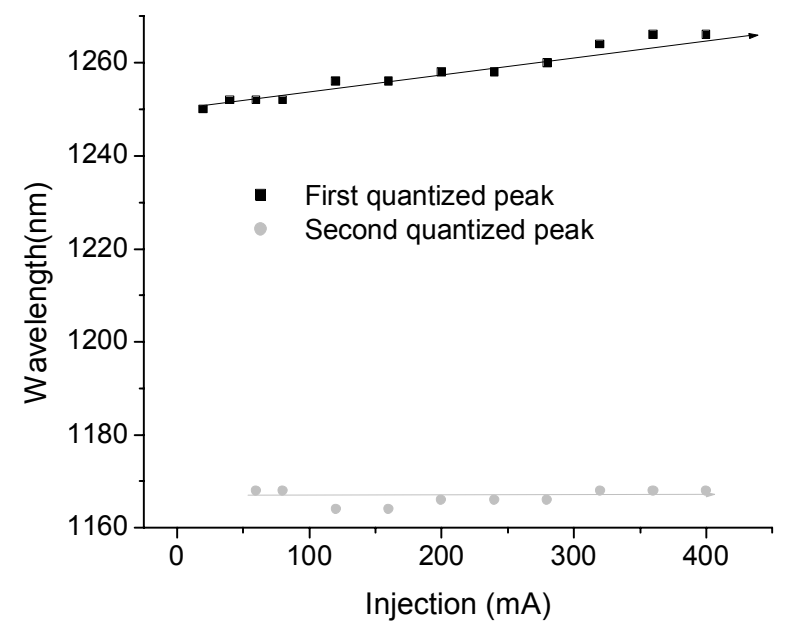

Fig. 3. The current - EL peak curve of $800 \mu \mathrm{m}$ device 
The emission spectrum of the $350 \mu \mathrm{m}$ device has the same shape. The peak emission power of the $1.25 \mu \mathrm{m}$ peak saturates at $40 \mathrm{~mA}$. Its peak position red shifts with increased current. This peak is at $1248 \mathrm{~nm}$ with $10 \mathrm{~mA}$ injection. It moves to $1260 \mathrm{~nm}$ when the injection current is increased to $80 \mathrm{~mA}$. The peak emission power of the $1.17 \mu \mathrm{m}$ peak does not saturate due to lower operation current density. The peak position blue shifts from $1172 \mathrm{~nm}$ to $1166 \mathrm{~nm}$ when the current is increased from $20 \mathrm{~mA}$ to $60 \mathrm{~mA}$. It shifts back to $1168 \mathrm{~nm}$ when the current is increased to $80 \mathrm{~mA}$.

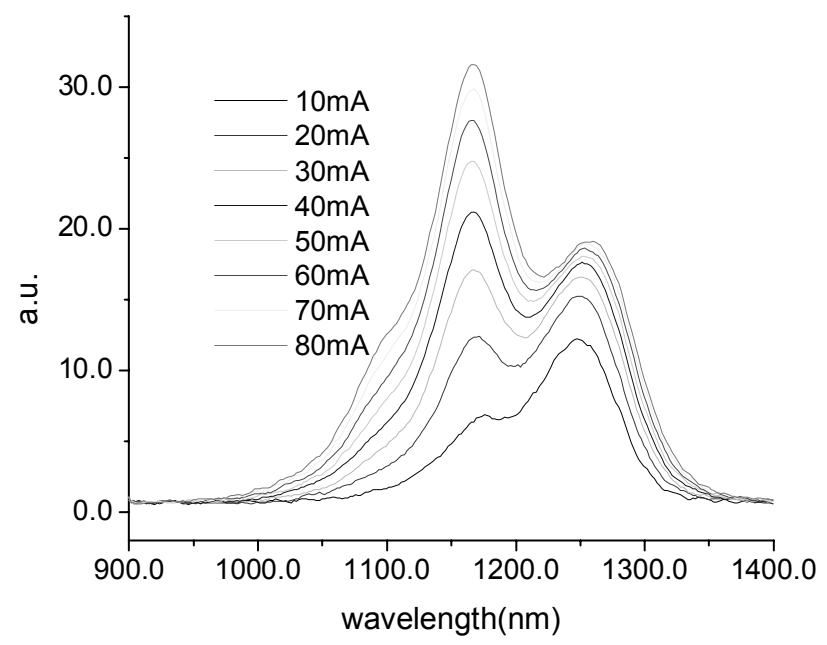

Fig. 4. The EL spectrum of $350 \mu \mathrm{m}$ device.

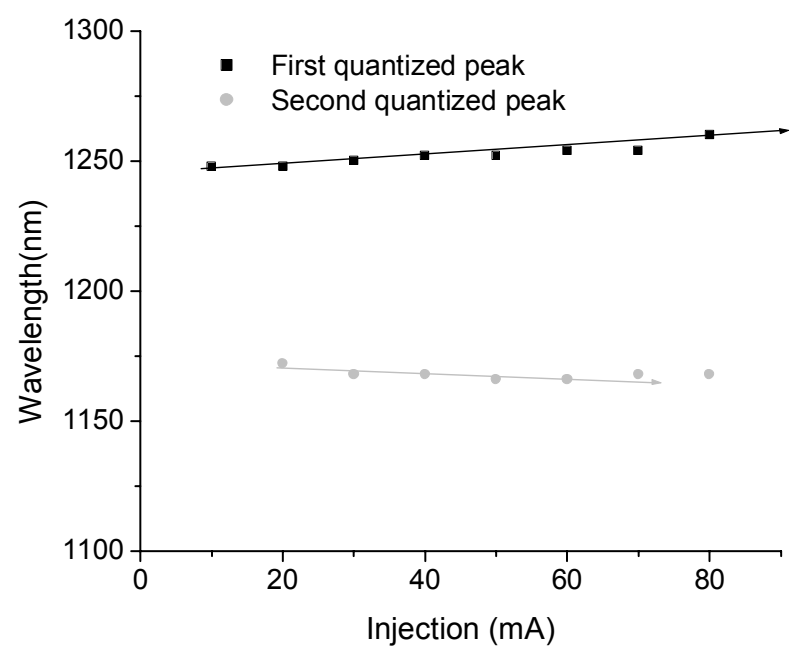

Fig. 5. The current - EL peak curve of $350 \mu \mathrm{m}$ device.

\section{DISCUSSION}

Several factors influence the emission peaks of the spectrum. In general, with increased injection current, the position of $1.25 \mu \mathrm{m}$ peak red shifts. This can be explained by bandgap narrowing due to increased active layer temperature. The same mechanisms effect should have the effect on the emission of the second quantized state. Thus, the emission peak wavelengths of both quantized states will increase with increasing current. In addition, the magnitude of red shift should approximately be the same because bandgap narrowing will change the positions of quantized states by the same amount.

Although, simultaneous red shift of both emission peaks is observed under high current density, $160 \mathrm{~mA}$ to $400 \mathrm{~mA}$ for $800 \mu \mathrm{m}$ device and $60 \mathrm{~mA}$ to $80 \mathrm{~mA}$ for $350 \mu \mathrm{m}$ device. The decreases of photon energy for both peaks are different. Photon energy of first quantized state decrease more than that of second quantized state, as shown in Fig. 6.

Another effect of increasing injection current is to change the distribution of carriers among different QDs. The origin of this effect is the different carrier capture abilities of QDs with different sizes and the state filling effect. Larger QDs have more chance to capture carriers because they occupy more volume. In addition, the quantized states of larger QDs have lower quantized energy. Thus, carriers tend to populate in larger QDs under equilibrium according to Fermi-Dirac distribution. Under very low injection density, most of the carriers will be captured by larger QDs. As injected current increase, the states of larger QDs are filled up, so more carriers will fall into smaller QDs.

Because the QDs in this sample have a large size variation, inhomogeneous broadening makes the observed emission bandwidth broad. The position of each observed emission peak is affected by both carrier distribution and quantized state position. If carriers tend to distribute at larger QDs, the emission peak will be at the longer wavelength. If carriers tend to distribute at smaller QDs, the emission peak will be at the shorter wavelength. In the observed devices, this effect makes the peak emission position of second quantized states blue shifted as current is increased from $60 \mathrm{~mA}$ to $160 \mathrm{~mA}$ for the $800 \mu \mathrm{m}$ device and $10 \mathrm{~mA}$ to $60 \mathrm{~mA}$ for the $350 \mu \mathrm{m}$ device. Under higher injection level, this effect is less important because the quantized states of smaller QDs are saturated also. Finally, thermal bandgap narrowing will dominate the direction of emission-peak shift.

The final issue is to explain the different behavior of both emission peaks. It is because the two quantized states have different density distribution. Because the position of quantized level depends on $\mathrm{n}^{2} . \mathrm{n}$ is 1 for the 
first quantized state and 2 for the second quantized state. The position of the second quantized level is more sensitive to the dot-size variation than the position of the first quantized level. Thus, the separation between the first and the second quantized levels of a smaller dot will be larger and it will be smaller for a larger dot. If carriers concentrate in larger dots, the separation between two emission peaks will be smaller. If carriers concentrate in smaller dots, the separation between two emission peaks will be larger. For this reason, the directions and amounts of shift of the two emission peaks must be different. The observed separation between the two emission peaks increases as current increases because the increased current will provide more carriers to smaller QDs than to larger QDs.

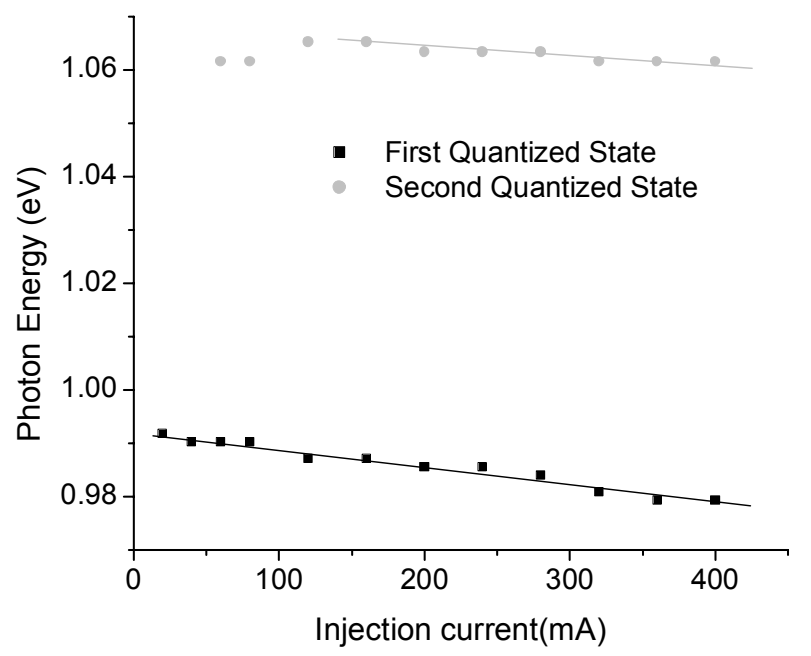

Fig. 6. The current - photon energy $800 \mu \mathrm{m}$ device.
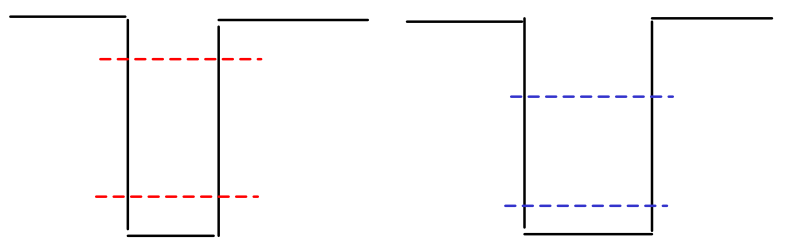

Small Dot

Large

Fig. 7. The relative position of quantized states in different size QDs.

\section{CONCLUSION}

In QD structures, carriers do not distribute uniformly among QDs. Carriers tend to distribute at larger QDs. Combined with state filling effect, it makes the emission peak of the second quantized state blue shift with increasing current. The nonuniform carrier distribution also leads to the separation of two emission peaks increasing with increased current. On the observed $800 \mu \mathrm{m}$ device, the photon energy difference between the two peaks increases from $70.8 \mathrm{meV}$ at $60 \mathrm{~mA}$ to $78 \mathrm{meV}$ at $160 \mathrm{~mA}$. By observing the peak separation, the tendency of carrier distribution can be identified.

\section{REFERENCES}

[1] Q. Xie, P. Chen, A. Kalburge, T. R. Ramachandran, A. Nayfonov, A. Konkar, and A. Madhukar, "Realization of optically active strained InAs island quantum boxes on GaAs (100) via molecular beam epitaxy and the role of island induced strain fields," J. Cryst. Growth, vol. 150, p. 357, 1995.

[2] P. M. Varangis, H. Li, G. T. Liu, T. C. Newell, A. Stintz, B. Fuchs, K. J. Malloy, and L. F. Lester, "Low-threshold quantum dot lasers with $201 \mathrm{~nm}$ tuning range," Electron. Lett., vol. 36, pp. 529-530, 2000.

[3] Bor-Lin Lee, Ching-Fuh Lin, and Jie-Wei Lai, "Experimental evidence of nonuniform carrier distribution in multiple-quantum well laser diodes," IEE Electron. Lett. Vol. 34, pp.1230-1231, 1998. 